\title{
INTEGRASI FMEA DALAM PENERAPAN QUALITY CONTROL CIRCLE (QCC) UNTUK PERBAIKAN KUALITAS PROSES PRODUKSI PADA MESIN TENUN RAPIER
}

\author{
Yudi Syahrullah ${ }^{1^{*}}$ dan Milenia Rahma Izza $^{2}$ \\ ${ }^{1,2}$ Program Studi Teknik Industri, Fakultas Teknik, Universitas Jenderal Soedirman \\ Jl. Mayjend Sungkono Km 5, Blater, Purbalingga 53371 \\ *email: yudi.syahrullah@unsoed.ac.id
}

\begin{abstract}
PT. Pajitex is one of the textile industries that produce sarongs and continues to strive to fulfill customer desires through quality sarong products. During the sarong production process, there are still various product defects that can reduce consumer confidence in the resulting sarong products. Therefore, PT. Pajitex strives to reduce the number of defects that occur in the sarong manufacturing process by exploring various causes of defects. The purpose of this study was to analyze the defective edge on the CR3082 plate using the Quality Control Circle (QCC) method. The QCC method is a quality control system through the 8-step method with a continuous improvement system. At the defect search stage, use quality control tools such as Pareto diagrams and fishbone diagrams, and use the Failure Mode Effect Analysis (FMEA) method to obtain the highest RPN value which is a priority in the improvement proposal, and in determining the improvement proposal using the PDCA Methods. Based on the results of the analysis obtained, the cutter cutting and the needling process are not perfect and the tuck-in setting is not precise has the highest RPN value, which is equal to 120, so this activity needs to be monitored and followed up.
\end{abstract}

Keywords: Improvement, Quality Control Circle, FMEA

\section{Pendahuluan}

Proses produksi yang dilakukan dengan memperhatikan dan memenuhi aspek kualitas dapat mengurangi jumlah defect atau cacat produk, sehingga kegiatan tersebut akan bebas dari kerusakan produk (Windarti, 2014) . Dengan begitu perusahaan dapat mengurangi pemborosan biaya produksi yang ditimbulkan akibat adanya defect dan lebih efisien dalam proses produksi. PT. Pajitex terus berupaya untuk mengurangi cacat yang diakibatkan oleh berbagai aspek selama proses produksi. Perusahaan ini merupakan perusahaan tekstil yang memproduksi berbagai jenis sarung, dengan aktifitas produksi mulai dari pengolahan bahan baku sampai menjadi produk akhir, yaitu sarung yang merupakan kain yang banyak digunakan oleh masyarakat Indonesia. PT. Pajitex menggunakan tipe produksi mass-production dengan pola aliran flow shop untuk produk lokal, sedangkan untuk produk ekspor dikerjakan berdasarkan spesifikasi pemesanan engineering to order (ETO).

Produk yang dihasilkan perusahaan dengan kualitas tidak baik (defect) memang bisa diperbaiki kembali (rework), tetapi hal tersebut akan berakibat pada biaya yang dikeluarkan perusahaan menjadi lebih besar dan munculnya komplain dari pelanggan akibat waktu pengiriman yang menjadi lebih lambat. Oleh karena itu, perusahaan berupaya untuk melakukan pengendalian kualitas pada produk yang dihasilkan perusahaan. Proses yang baik dan sesuai dengan standar kualitas akan menghasilkan kualitas yang baik yang dapat kemampuan bersaing perusahaan (Darsono, 2013). Pengendalian kualitas dilakukan agar produk maupun jasa yang dihasilkan oleh perusahaan dapat sesuai dengan standar mutu yang diinginkan dan ditetapkan, serta melakukan perbaikan kualitas untuk produk atau jasa yang dihasilkan dan belum sesuai standar mutu tersebut (Ratnadi \& Suprianto, 2016)

Salah satu permasalahan yang sering menyebabkan terjadinya defect pada produk yang dihasilkan oleh PT. Pajitex adalah proses produksi dengan menggunakan mesin tenun rapier. Perlu dilakukan upaya untuk meningkatkan kualitas dengan mengurangi defect pada proses tenun dengan menggunakan mesin rapier ini. Penelitian tentang perbaikan kualitas telah dilakukan oleh beberapa peneliti, diantaranya Fachry Hafid \& Muh Syukur Yusuf (2018), Hendrawan et al., (2016) dan Wicaksono \& Syahrullah (2020). Penelitian tentang perbaikan kualitas tersebut menggunakan Metode 
Quality Control Circle (QCC) untuk meningkatkan kinerja kualitas pada objek yang diteliti. Pada penelitian tentang QCC tersebut sebagian besar menggunakan seven tools dan PDCA,pada penelitian ini metode FMEA untuk mendapatkan prioritas dalam usulan perbaikan diintegrasikan kedalam langkah - langkah QCC dengan menggunakan pendekatan PDCA. Metode ini digunakan agar perusahaan dapat lebih fokus pada penyebab yang paling banyak menyebabkan defect sehingga dapat mengurangi risiko sekaligus digunakan secara terus menerus dalam perbaikan kualitas hasil dari proses produksi. Penelitian ini dilakukan dengan tujuan untuk menentukan penyebab terjadinya defect dan mengurangi terjadinya defect pada proses produksi pada mesin rapier dengan menentukan beberapa prioritas perbaikan yang akan dilakukan. Penentuan prioritas perbaikan ini dilakukan dengan menggunakan mengintegrasikan FMEA kedalam langkah langkah QCC

\section{Landasan Teori}

Menurut Bastian (2006) dalam penelitian (Rahayu et al., 2020), defect adalah produk yang dihasilkan dalam proses produksi, dimana produk yang dihasilkan tersebut tidak sesuai dengan standar mutu yang ditetapkan. Perusahaan berupaya mengurangi defect atau cacat produksi dengan berbagai upaya untuk memenuhi kepuasan pelanggan. Salah satu upaya yang dapat dilakukan untuk mengurangi defect adalah dengan mengendalikan kualitas dan melakukan perbaikan kualitas selama proses produksi. Salah satu metode yang sering digunakan oleh perusahaan dalam memperbaiki kualitas adalah Quality Control Circle atau disingkat QCC.

Gasperz (2011) dalam (Khamaludin \& Respati, 2019) menyatakan bahwa QCC merupakan sekelompok karyawan atau pekerja yang berupaya memperbaiki kualitas dan efisiensi produksi secara sukarela dengan mengadakan pertemuan - pertemuan secara berkala untuk melakukan perbaikan berkesinambungan. Sekelompok karyawan tersebut membentuk sebuah tim yang dipimpin oleh seorang leader dan dipantau oleh seorang fasilitator yang sudah ditetapkan oleh perusahaan.

\subsection{Quality Control Circle}

Metode yang digunakan untuk perbaikan kualitas yaitu Quality Control Circle (QCC). Menurut Prof. Kaoru Ishikawa Quality Control Circle (QCC) adalah sebuah sistem pengendalian kualitas melalui metode 8 langkah dengan sistem perbaikan berkesinambungan atau kaizen. Alat pengendalian kualitas yang digunakan pada metode QCC ini yaitu seven tools. QC Seven
Tools adalah tujuh alat dasar yang digunakan untuk memecahkan permasalahan yang dihadapi oleh produksi, terutama untuk meningkatkan kemampuan perbaikan proses (Andre Arief Hendrawan, Yustina, 2016). Sehingga terdapat peningkatan kompetisi, penurunan biaya, dan peningkatan produktivitas kerja. Penerapan QCC untuk meminimalkan binning loss dengan langkah-langkah sebagai berikut (Fachry Hafid \& Muh Syukur Yusuf, 2018):

1. Menentukan Tema

2. Penetapan Target

3. Analisa Kondisi Ada

4. Analisa Sebab Akibat

5. Rencana Penanggulangan

6. Pelaksanaan Penanggulangan

7. Evaluasi Hasil

8. Standarisasi dan Tindak Lanjut

Beberapa alat dalam seven tools untuk tahapan kegiatan dalam implementasi QCC, diantaranya : pareto dan fishbone diagram. Pareto diagram digunakan untuk mencari permasalahan yang paling dominan terjadi dan Fishbone diagram digunakan untuk menulusuri penyebab defect terjadi (Fachry Hafid \& Muh Syukur Yusuf, 2018).

\subsection{Failure Mode and Effects Analysis dan PDCA}

Metode untuk mencari penyebab kegagalan atau metode Failure Mode Effect Analysis (FMEA) digunakan untuk memperoleh nilai RPN tertinggi yang menjadi prioritas dalam usulan perbaikan. FMEA merupakan metode yang dapat digunakan untuk mengendalikan kualitas (Puspitasari \& Martanto, 2014). FMEA digunakan untuk mencari, mengidentifikasi dan menghilangkan kegagalan yang potensial terjadi pada system. FMEA menentukan prioritas risiko berdasarkan tingkat keparah (severity), kemungkinan terjadinya (occurrance), serta kemungkinan terdeteksinya sebuah kegagalan yang terjadi (detection). Tabel 1 merupakan klasifikasi RPN yang digunakan dalam metode FMEA (Desy et al., 2014) :

Tabel 1. Tabel Klasifikasi RPN

\begin{tabular}{cc}
\hline RPN & Calculation Level \\
\hline $0-19$ & Very Low \\
$20-79$ & Low \\
$80-119$ & Medium \\
$120-199$ & High \\
\hline$>199$ & Very High \\
\hline
\end{tabular}

Kemudian untuk melakukan perbaikan menggunakan pendekatan siklus Plan, Do, Check, 
Act (PDCA). Pendekatan ini diperkenalkan oleh W.E. Deming dan WA Shewhart, sehingga siklus PDCA ini juga dikenal sebagai siklus Deming atau siklus pengendalian yang kemudian dalam perkembangannya lebih dikenal sebagai delapan langkah perbaikan kualitas, metode PDCA memberikan tahapan proses pemecahan masalah yang terukur dan akurat. Metode PDCA termasuk dalam Total Quality Management (TQM) yang dilakukan secara bertahap dalam upaya untuk memenuhi kepuasan pelanggan. Menurut (Nasution et al., 2018) berikut merupakan penjelasan dari tiap tahapan PDCA:

1. Plan (Mengidentifikasi masalah, spesifikasi masalah, dan pengumpulan data).

2. Do (Melakukan, meliputi analisis data membuat kesimpulan tentatif)

3. Check (Periksa kesimpulan statistik)

4. Action (Tindakan untuk mempertahankan hasil perbaikan)

Perbaikan kualitas proses pengecoran dapat diselesaikan dengan menggunakan metode QCC dengan pendekatan PDCA (Wicaksono \& Syahrullah, 2020) . Dimana pada tahapan plan, tools digunakan untuk menggambarkan kondisi saat ini dengan menggunakan diagram pareto, QCDSME vs $4 \mathrm{M}+1 \mathrm{E}$, dan fishbone diagram. Pada tahap Do, aktivitas yang dilakukan antara yaitu dengan mengimplementasikan improvement. Pada tahap check, dilakukan evaluasi terhadap efek dari implementasi yang dilakukan pada tahap Do. Namun penulis hanya melakukan simulasi atau mengilustrasikan suatu keadaan dimana produk sudah lolos dari tahapan pengecekan setelah itu dapat diketahui perkiraan dampak apa yang akan terjadi sehingga persentase reject menurun, tools yang digunakan yaitu diagram pareto. Kemudian pada tahap action, dihasilkan saran atau rekomendasi standarisasi berdasarkan potensi masalah yang ada berdasarkan faktor yang menyebabkan defect.

\section{Metode Penelitian}

Metode yang digunakan pada penelitian ini adalah Quality Control Circle (QCC). Pada tahap awal, pengumpulan data dilakukan dengan Teknik pengumpulan data kualitatif menggunakan metode wawancara. Wawancara dilakukan dengan bagian yang berkaitan dengan Kualitas dan Produksi. Wawancara dilakukan dengan Kepala Bagian QC dan Produksi untuk mengidentifikaasi permasalahan yang terjadi.

Pada tahap berikutnya, berdasarkan hasil pengolahan data tahap awal, dilakukan beberapa tahapan dalam implementasi QCC dengan melakukan brainstorming dan wawancara untuk menentukan tema (langkah 1) dan target (langkah 2) yang ingin dicapai dengan kaidah SMART
(Specific - Measurable - Achievable Reasonable - Time). Pada tahap ini dilakukan pengumpulan data dengan Teknik pengumpulan data secara kuantitatif berdasarkan data historis selama periode pengamatan, yaitu pada bulan Mei sampai dengan bulan Juli 2020.

Pada tahap berikutnya dilakukan pengamatan yang lebih mendalam dengan observasi langsung pada lantai produksi dan menganalisis kondisi proses produksi (langkah 3) dan dilanjutkan dengan 5 tahapan berikutnya. Seven tools digunakan pada beberapa tahapan implementasi QCC. Kemudian menggunakan metode FMEA untuk menentukan prioritas dalam usulan perbaikan yang dilakukan dengan metode PDCA.

\section{Hasil Dan Pembahasan}

Pada bagian ini akan membahas mengenai analisis dan pembahasan dari permasalahan menggunakan metode QCC dengan bantuan alat seven tools, FMEA dan PDCA. Metode QCC ini memiliki beberapa langkah-langkah, berikut merupakan penjabarannya:

\subsection{Menentukan Tema}

Data yang dipakai yaitu dari periode Mei-Juli 2020, dengan data defect dari 3 besar mesin terbanyak yang sering dioperasikan, yaitu mesin Tsudakoma AJL, China Rapier dan Shuttle dengan perhitungan defect nya 5 besar tertinggi yang ada diperusahaan. Kemudian diurutkan berdasarkan jumlah defect dari yang paling banyak sampai yang paling sedikit. Pada Gambar 1. merupakan data defect periode Mei-Juli 2020.

(\%) Defect

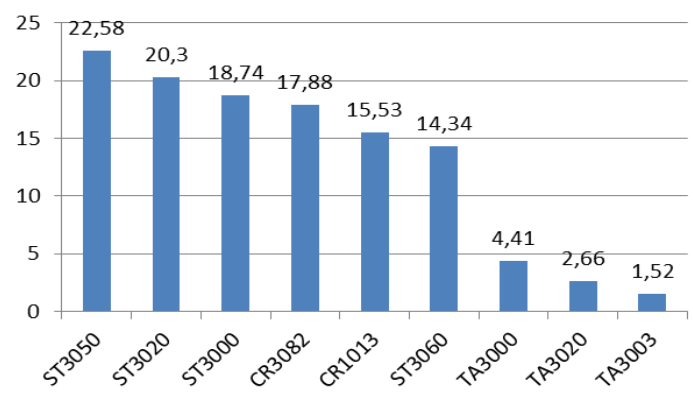

Gambar 1. Urutan Defect Periode Mei-Juli 2020.

Dari diagram diatas dapat diketahui jika Palekat ST3050 (mesin shuttel) merupakan penghasil defect terbanyak. Namun pada PT. Pajitex mesin Shuttel (ST3050, ST3020, dan ST 3000) ini mulai tidak dioperasikan lagi dikarenakan umur mesin yang sudah sangat lama. Hal tersebut menyebabkan kinerja mesin yang sudah mulai turun sehingga produktivitas rendah dan jumlah produk cacat pada mesin ini tinggi. Oleh karena itu perusahaan akan mengganti 
dengan mesin terbaru yang kinerjanya menjadi lebih sedikit. Pada penelitian ini, pemilihan mesin diprioritaskan pada mesin yang masih digunakan dalam proses produksi pada periode berikutnya, seperti mesin dengan kode CR dan TA.

Dapat dilihat pada jumlah defect terbesar urutan ke empat yaitu mesin Rapier pada Palekat CR3082, sehingga mesin Rapier Palekat CR3082 akan menjadi titik fokus penelitian. Setelah mengetahui jenis mesin Palekat yang akan dijadikan objek observasi, selanjutnya perlu diketahui jenis defect apa saja yang terjadi pada Palekat CR3082. Berdasarkan observasi, diperoleh 25 jenis defect untuk Palekat CR3082. Selanjutnya dilakukan pemilihan defect dengan prioritas 10 jenis defect yang paling sering terjadi pada Palekat CR3082. Pada Gambar 2. dibawah ini merupakan jenis defect yang terjadi pada Palekat CR3082, serta dapat mengetahui tingkatan defect tertinggi pada Palekat CR3082 dengan menggunakan alat diagram pareto.

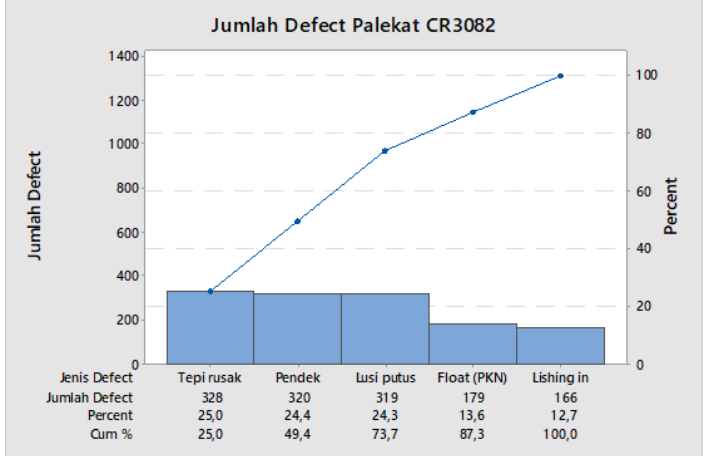

Gambar 2. Jumlah Defect Palekat CR3082 Periode Mei-Juli 2020

Dari hasil diagram pareto tersebut dapat disimpulkan bahwa tepi rusak berada pada urutan tertinggi dengan jumlah defect sebanyak 328 pada periode Mei-Juli 2020. Sehingga penulis dapat mengambil permasalahan, yaitu menganalisa terjadinya defect tepi rusak terhadap Palekat CR3082 pada mesin Rapier.

\subsection{Menetapkan Target}

Berdasarkan data hasil proses produksi selama bulan Mei sampai dengan Juli 2020 rata - rata produk berkualitas baik (Good) sekitar 95\% (untuk semua jenis mesin) seperti tercantum pada Tabel 2 dibawah.

Tabel 2. Presentase Defect Tepi Rusak

\begin{tabular}{ccc}
\hline Bulan & Good (\%) & Defect (\%) \\
Mei & 93,8 & 6,2 \\
Juni & 95,7 & 4,3 \\
Juli & 95,8 & 4,3 \\
\hline
\end{tabular}

Berdasarkan data pada Tabel 2, dilakukan diskusi dengan Kepala Bagian QC untuk menetapkan target implementasi QCC dengan menggunakan kaidah SMART . Berdasarkan hasil wawancara tersebut, ditetapkan target dengan rincian sebagai berikut:

1. Specific: Defect tepi rusak pada mesin Rapier turun

2. Measurable: Defect tepi rusak pada mesin Rapier turun maksimal 2\%

3. Achievable: Target dapat tercapai dengan analisis $4 \mathrm{M}+1 \mathrm{E}$

4. Reasonable: Didasarkan \% defect sebelum dilakukan perbaikan pada bulan Mei-Juli sebesar 4,9\% kemudian pada bulan September $\%$ defect menjadi sebesar 2,9\%

5. Time Base: Target tercapai di bulan September 2020

\subsection{Analisis Kondisi Yang Ada (Anakonda)}

Setelah pengumpulan data defect Palekat CR3082 pada mesin Rapier, diperoleh defect tepi rusak merupakan defect dengan jumlah tertinggi, yaitu sebesar 328 kejadian. Selanjutnya dilakukan analisis untuk menemukan faktor penyebab terjadinya defect tepi rusak pada Palekat CR3082 mesin Rapier. Analisis menggunakan pendekatan 4M1E yaitu man, machine, methode, material dan environment. Hasil analisis yang didapatkan dapat dilihat pada Tabel 3. dibawah ini

Tabel 3. Faktor Penyebab Masalah

\begin{tabular}{|c|c|c|}
\hline Masalah & $\begin{array}{c}\text { Kondisi yang } \\
\text { ada }\end{array}$ & Kondisi Ideal \\
\hline $\begin{array}{l}\text { Manusia } \\
\text { Cucuk }\end{array}$ & $\begin{array}{l}\text { Pemasangan } \\
\text { benang lusi ke } \\
\text { bagian cucuk } \\
\text { tidak sesuai } \\
\text { SOP }\end{array}$ & $\begin{array}{l}\text { Benang lusi } \\
\text { yang dipasang } \\
\text { di cucuk harus } \\
\text { sesuai SOP }\end{array}$ \\
\hline $\begin{array}{l}\text { Material } \\
\text { Handling }\end{array}$ & $\begin{array}{l}\text { Pada saat } \\
\text { material } \\
\text { handling antar } \\
\text { departemen } \\
\text { menggunakan } \\
\text { forklift tidak } \\
\text { hati-hati } \\
\text { sehingga } \\
\text { sarung bagian } \\
\text { tepi dapat } \\
\text { tergores }\end{array}$ & $\begin{array}{l}\text { Penggunaan } \\
\text { forklift antar } \\
\text { departemen } \\
\text { dilakukan secara } \\
\text { hati-hati }\end{array}$ \\
\hline Mending & $\begin{array}{l}\text { Pemotongan } \\
\text { tepi } \\
\text { menggunakan } \\
\text { gunting oleh } \\
\text { operator tidak } \\
\text { teliti sehingga } \\
\text { akan } \\
\text { menyobek }\end{array}$ & $\begin{array}{l}\text { Pemotongan } \\
\text { tepi sarung } \\
\text { dengan gunting } \\
\text { dilakukan } \\
\text { dengan hati-hati }\end{array}$ \\
\hline
\end{tabular}




\begin{tabular}{|c|c|c|}
\hline Masalah & $\begin{array}{c}\text { Kondisi yang } \\
\text { ada }\end{array}$ & Kondisi Ideal \\
\hline & bagian tepi & \\
\hline $\begin{array}{l}\text { Mesin } \\
\text { Calender }\end{array}$ & $\begin{array}{l}\text { Operator tidak } \\
\text { teliti terhadap } \\
\text { sarung yang } \\
\text { terlipat } \\
\text { sehingga akan } \\
\text { terproses dan } \\
\text { menyebabkan } \\
\text { glossy }\end{array}$ & $\begin{array}{l}\text { Operator } \\
\text { mengamati } \\
\text { bagian sarung } \\
\text { yang terlipat dan } \\
\text { memperbaikinya } \\
\text { sehingga tidak } \\
\text { terjadi glossy }\end{array}$ \\
\hline $\begin{array}{l}\text { Mesin } \\
\text { Gun }\end{array}$ & $\begin{array}{l}\text { Pergerakan } \\
\text { gun tidak } \\
\text { sempurna }\end{array}$ & $\begin{array}{l}\text { Pergerakan gun } \\
\text { sempurna }\end{array}$ \\
\hline $\begin{array}{l}\text { Cutter, } \\
\text { needle }\end{array}$ & $\begin{array}{l}\text { Pemotongan } \\
\text { oleh cutter } \\
\text { tidak } \\
\text { sempurna, } \\
\text { sehingga } \\
\text { ketika tuckin } \\
\text { menarik sisa } \\
\text { benangnya } \\
\text { akan } \\
\text { mengekor } \\
\text { pada hasil } \\
\text { pertenunan }\end{array}$ & $\begin{array}{l}\text { Pemotongan } \\
\text { cutter sempurna, } \\
\text { penarikan tuckin } \\
\text { sempurna }\end{array}$ \\
\hline $\begin{array}{l}\text { Bakar } \\
\text { bulu, } \\
\text { washing }\end{array}$ & $\begin{array}{l}\text { Press magle } \\
\text { terlalu kuat } \\
\text { dan } \\
\text { mengakibatkan } \\
\text { sarung jenis } \\
\text { rayon pada } \\
\text { bagian tepi } \\
\text { akan rusak }\end{array}$ & $\begin{array}{l}\text { Press magle } \\
\text { berjalan sesuai } \\
\text { SOP }\end{array}$ \\
\hline \multicolumn{3}{|l|}{ Metode } \\
\hline Tuckin & $\begin{array}{l}\text { Pengaturan } \\
\text { pada saat } \\
\text { menyetel } \\
\text { tuckin tidak } \\
\text { tepat sehingga } \\
\text { tidak dapat } \\
\text { bekerja sama } \\
\text { dengan } \text { cutter }\end{array}$ & $\begin{array}{l}\text { Pengaturan } \\
\text { tuckin harus } \\
\text { tepat }\end{array}$ \\
\hline \multicolumn{3}{|c|}{ Lingkungan } \\
\hline Suhu & $\begin{array}{l}\text { Suhu pada } \\
\text { departemen } \\
\text { tidak sesuai } \\
\text { standar ISO, } \\
\text { yaitu terlalu } \\
\text { panas }\end{array}$ & $\begin{array}{l}\text { Suhu tiap } \\
\text { departemen } \\
\text { harus sesuai } \\
\text { standar ISO }\end{array}$ \\
\hline
\end{tabular}

\subsection{Analisis Sebab Akibat}

Pada tahapan analisa sebab akibat menggunakan tools dari seven tools yaitu diagram sebab akibat atau biasa disebut diagram tulang ikan (fishbone diagram) serta penggunakan metode FMEA. Diagram fishbone sangat bermanfaat untuk mencari faktor - faktor penyebab dalam hal ini faktor yang menyebabkan defect tepi rusak pada Palekat CR3082. Sesuai hasil analisis pada tahap sebelumnya pada tabel 3 , analisis sebab akibat ini menggunakan 4 faktor, yaitu manusia, metode, mesin dan lingkungan. Sementara faktor lain yang biasanya digunakan pada analisis sebab akibat, yaitu faktor material atau bahan baku tidak digunakan karena faktor ini dinilai tidak berpengaruh terhadap defect yang ingin diperbaiki. Hasil analisis sebab akibat atau fishbone diagram dari defect tepi rusak pada Palekat CR3082 selanjutnya ditampilkan pada gambar 3 .

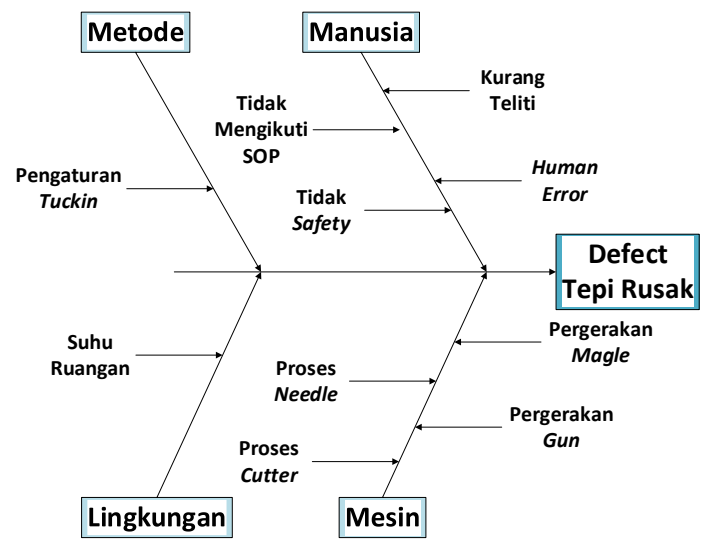

Gambar 3. Diagram fishbone

Selanjutnya berdasarkan hasil analisis sebab akibat pada gambar 3, dilakukan analisis dengan menggunakan metode FMEA. FMEA digunakan untuk memperoleh faktor penyebab defect yang paling potensial terjadi. Faktor penyebab defect yang paling diprioritaskan untuk dilakukan improvement berdasarkan nilai Risk Priority Number (RPN) yang paling besar. Nilai RPN terbesar mengindikasikan faktor tersebut memiliki risiko kejadian defect dan dampak defect yang cukup besar. Untuk perhitungan RPN, data yang dibutuhkan antara lain adalah tingkat keparahan dari akar masalah (severity / sev.), frekuensi terjadinya defect akibat sebuah akar permasalahan (occurance / occ.), dan kesulitan untuk melakukan deteksi terhadap gejala defect yang ditimbulkan oleh sebuah akar permasalahan (detection / det.). Berdasarkan hasil analisis sebab akibat pada tahap sebelumnya, diperoleh hasil analisis FMEA pada tabel 4. 
Tabel 4. Analisis FMEA Berdasarkan Fishbone Diagram

\begin{tabular}{|c|c|c|c|c|}
\hline Cause & Sev. & Occ. & Det. & RPN \\
\hline Manusia & & & & \\
\hline $\begin{array}{l}\text { Kurang teliti pada } \\
\text { mesin calender, } \\
\text { menyebabkan } \\
\text { glossy }\end{array}$ & 5 & 3 & 2 & 30 \\
\hline $\begin{array}{lr}\text { Kurang } & \text { safety } \\
\text { dalam } & \text { material } \\
\text { handling } & \end{array}$ & 8 & 2 & 1 & 16 \\
\hline $\begin{array}{l}\text { Pemasangan } \\
\text { benang lusi ke } \\
\text { cucuk tidak sesuai } \\
\text { SOP }\end{array}$ & 6 & 4 & 4 & 96 \\
\hline $\begin{array}{l}\text { Pemotongan tepi } \\
\text { sarung tidak sesuai } \\
\text { SOP }\end{array}$ & 5 & 3 & 3 & 45 \\
\hline $\begin{array}{l}\text { Mesin } \\
\text { Pergerakan gun } \\
\text { tidak sempurna }\end{array}$ & 4 & 2 & 8 & 64 \\
\hline $\begin{array}{l}\text { Press magle terlalu } \\
\text { kuat }\end{array}$ & 1 & 1 & 9 & 9 \\
\hline $\begin{array}{l}\text { Pemotongan cutter } \\
\text { dan proses needle } \\
\text { tidak sempurna }\end{array}$ & 6 & 10 & 2 & 120 \\
\hline Metode & & & & \\
\hline $\begin{array}{l}\text { Pengaturan tuckin } \\
\text { kurang tepat }\end{array}$ & 6 & 10 & 2 & 120 \\
\hline $\begin{array}{l}\text { Suhu pada tiap } \\
\text { departemen } \\
\text { sesuai standar } \\
\text { Lingkungan }\end{array}$ & 2 & 5 & 1 & 10 \\
\hline $\begin{array}{l}\text { Suhu pada tiap } \\
\text { departemen tidak } \\
\text { sesuai standar }\end{array}$ & 2 & 5 & 1 & 10 \\
\hline
\end{tabular}

Berdasarkan nilai RPN yang telah dihitung, diambil tiga peringkat teratas yang berarti sangat butuh dan diprioritaskan untuk dicari usulan perbaikannya. Tabel 5 menunjukkan peringkat RPN berdasarkan akar penyebab masalah pada defect tepi rusak.

Tabel 5. Peringkat RPN Penyebab Defect Tepi Rusak

\begin{tabular}{|c|c|c|c|c|}
\hline No & Faktor & $\begin{array}{c}\text { Cause RPN } \\
\text { tertinggi }\end{array}$ & RPN & Cat. \\
\hline 1 & Mesin & $\begin{array}{l}\text { Pemotongan } \\
\text { cutter dan } \\
\text { proses needle } \\
\text { tidak } \\
\text { sempurna }\end{array}$ & 120 & High \\
\hline 2 & Metode & $\begin{array}{l}\text { Pengaturan } \\
\text { tuckin kurang } \\
\text { tepat }\end{array}$ & 120 & High \\
\hline 3 & Manusia & \begin{tabular}{ll}
\multicolumn{2}{l}{ Pemasangan } \\
benang lusi \\
ke cucuk \\
tidak sesuai \\
SOP & \\
\end{tabular} & 96 & Medium \\
\hline
\end{tabular}

\subsection{Rencana Penanggulangan}

Dari hasil analisis dengan pendekatan FMEA, diperoleh 3 prioritas usualan perbaikan yang akan dilakukan. Usulan rencana penanggulangan diperoleh melalui diskusi dengan pihak perusahaan dan ditampilkan pada tabel 6 dibawah ini

Tabel 6. Rencana Penanggulangan

\begin{tabular}{|c|c|c|c|}
\hline No & Faktor & Cause & $\begin{array}{c}\text { Rencana } \\
\text { Penanggulangan }\end{array}$ \\
\hline 1 & Mesin & $\begin{array}{l}\text { Pemotong } \\
\text { an cutter } \\
\text { dan proses } \\
\text { needle } \\
\text { tidak } \\
\text { sempurna }\end{array}$ & $\begin{array}{l}\text { Pada saat benang } \\
\text { lusi diproses dan } \\
\text { digulung pada } \\
\text { beem,dilakukan } \\
\text { penyetelan ulang }\end{array}$ \\
\hline 2 & Metode & $\begin{array}{l}\text { Pengatura } \\
\text { n tuckin } \\
\text { kurang } \\
\text { tepat }\end{array}$ & $\begin{array}{l}\text { Diatur ulang } \\
\text { bagian tuckin } \\
\text { pada mesin } \\
\text { Rapier sebelum } \\
\text { dilakukan proses } \\
\text { pertenunan }\end{array}$ \\
\hline 3 & Manusia & $\begin{array}{l}\text { Pemasang } \\
\text { an benang } \\
\text { lusi ke } \\
\text { cucuk } \\
\text { tidak } \\
\text { sesuai } \\
\text { SOP }\end{array}$ & $\begin{array}{l}\text { Dilakukan } \\
\text { training dan } \\
\text { edukasi terhadap } \\
\text { karyawan } \\
\text { sebelum } \\
\text { melakukan } \\
\text { proses } \\
\text { pemasangan lusi } \\
\text { ke cucuk }\end{array}$ \\
\hline
\end{tabular}

\subsection{Pelaksanaan Penanggulangan}

Dari rencana penanggulangan yang telah ditetapkan, perusahaan perlu menetapkan mekanisme untuk pelaksanaan penanggulangan. Usulan pelaksanaan penanggulangan berikut ini diberikan berdasarkan diskusi dengan pihak perusahaan pada tabel 7 dibawah ini.

Tabel 7. Pelaksanaan Penanggulangan

\begin{tabular}{ccll}
\hline No. & Faktor & $\begin{array}{c}\text { Cause } \\
\text { RPN } \\
\text { tertinggi }\end{array}$ & $\begin{array}{l}\text { Pelaksanaan } \\
\text { Penanggulangan }\end{array}$ \\
1 & Mesin & $\begin{array}{l}\text { Pemotongan } \\
\text { cutter dan } \\
\text { proses } \\
\text { needle tidak } \\
\text { sempurna }\end{array}$ & $\begin{array}{l}\text { Mengganti atau } \\
\text { mengasah cutter } \\
\text { yang sudah } \\
\text { tumpul }\end{array}$ \\
\hline & Metode & $\begin{array}{l}\text { Pengaturan } \\
\text { tuckin } \\
\text { kurang tepat }\end{array}$ & $\begin{array}{l}\text { Mengganti tuckin } \\
\text { yang sudah tidak } \\
\text { bekerja maksimal }\end{array}$ \\
& &
\end{tabular}




\begin{tabular}{|c|c|c|c|}
\hline No. & Faktor & $\begin{array}{c}\text { Cause } \\
\text { RPN } \\
\text { tertinggi }\end{array}$ & $\begin{array}{c}\text { Pelaksanaan } \\
\text { Penanggulangan }\end{array}$ \\
\hline 3 & Manusia & $\begin{array}{l}\text { Pemasangan } \\
\text { benang lusi } \\
\text { ke cucuk } \\
\text { tidak sesuai } \\
\text { SOP }\end{array}$ & $\begin{array}{l}\text { dengan yang baru } \\
\text { Melakukan } \\
\text { training dan } \\
\text { edukasi pada saat } \\
\text { perekrutan } \\
\text { karyawan }\end{array}$ \\
\hline
\end{tabular}

\subsection{Evaluasi Hasil}

Setelah dilakukan rencana penanggulangan dan pelaksanaan penanggulangan, kemudian dilakukan pemantauan dari hasil yang sudah dilakukan. Tabel 8 merupakan evaluasi hasil yang didapat dari diskusi dengan pihak perusahaan:

Tabel 8. Evaluasi Hasil

\begin{tabular}{|c|c|c|c|}
\hline No. & Faktor & $\begin{array}{c}\text { Cause RPN } \\
\text { tertinggi }\end{array}$ & Evaluasi Hasil \\
\hline 1 & Mesin & $\begin{array}{l}\text { Pemotongan } \\
\text { cutter dan } \\
\text { proses needle } \\
\text { tidak } \\
\text { sempurna }\end{array}$ & $\begin{array}{l}\text { Operator yang } \\
\text { berada pada } \\
\text { bagian mesin, } \\
\text { meng- } \\
\text { informasikan } \\
\text { keadaan mesin } \\
\text { kepada } \\
\text { pengawas } \\
\text { mekanik setiap } \\
\text { hari }\end{array}$ \\
\hline 2 & Metode & $\begin{array}{l}\text { Pengaturan } \\
\text { tuckin kurang } \\
\text { tepat }\end{array}$ & $\begin{array}{l}\text { Operator yang } \\
\text { berada pada } \\
\text { bagian mesin, } \\
\text { meng- } \\
\text { informasikan } \\
\text { pengaturan } \\
\text { tuckin kepada } \\
\text { pengawas / } \\
\text { mekanik setiap } \\
\text { hari }\end{array}$ \\
\hline 3 & Manusia & $\begin{array}{l}\text { Pemasangan } \\
\text { benang lusi ke } \\
\text { cucuk tidak } \\
\text { sesuai SOP }\end{array}$ & $\begin{array}{l}\text { Operator pada } \\
\text { bagian cucuk } \\
\text { meng- } \\
\text { komunikasikan } \\
\text { dengan } \\
\text { pengawas setiap } \\
\text { hari }\end{array}$ \\
\hline
\end{tabular}

\subsection{Standarisasi dan Rencana Berikutnya}

Setelah dilakukan rencana penanggulangan, pelaksanaan penanggulangan, pemantauan dari hasil yang sudah dilakukan, perusahaan harus melakukan standarisasi serta rencana berikutnya agar defect tidak naik serta kualitas produknya meningkat. Standarisasi dan rencana berikutnya diperoleh dengan melakukan observasi terhadap penanggung jawab aktivitas terkait dari pihak perusahaan dan hasil observasi tersebut ditunjukkan pada Tabel 8 berikut ini.

Tabel 8. Standarisasi dan Rencana Berikutnya

\begin{tabular}{|c|c|c|c|}
\hline No. & Faktor & $\begin{array}{c}\text { Cause RPN } \\
\text { tertinggi }\end{array}$ & Evaluasi Hasil \\
\hline 1 & Mesin & $\begin{array}{l}\text { Pemotongan } \\
\text { cutter dan } \\
\text { proses needle } \\
\text { tidak } \\
\text { sempurna }\end{array}$ & $\begin{array}{l}\text { Dibuatkannya } \\
\text { jadwal perawatan } \\
\text { alat-alat dan mesin } \\
\text { secara rutin setiap } \\
\text { sebulan sekali baik } \\
\text { untuk alat-alat yang } \\
\text { akan rusak/aus } \\
\text { ataupun untuk alat- } \\
\text { alat yang masih } \\
\text { bagus sekalipun. }\end{array}$ \\
\hline 2 & Metode & $\begin{array}{l}\text { Pengaturan } \\
\text { tuckin } \\
\text { kurang tepat }\end{array}$ & $\begin{array}{l}\text { Dibuatkannya check } \\
\text { sheet untuk setiap } \\
\text { metode pengecekan } \\
\text { alat-alat khususnya } \\
\text { di area pertenunan } \\
\text { agar lebih terkontrol }\end{array}$ \\
\hline 3 & Manusia & $\begin{array}{l}\text { Pemasangan } \\
\text { benang lusi } \\
\text { ke cucuk } \\
\text { tidak sesuai } \\
\text { SOP }\end{array}$ & $\begin{array}{l}\text { Dibuatkannya SOP } \\
\text { pemasangan lusi ke } \\
\text { cucuk yang benar } \\
\text { agar menjadi } \\
\text { pedoman } r \text { untuk } \\
\text { operator } \\
\text { bekerja yang } \\
\text { tidak ada lagi } \\
\text { pemasangan lusi ke } \\
\begin{array}{l}\text { cucuk yang tidak } \\
\text { benar. }\end{array}\end{array}$ \\
\hline
\end{tabular}

\section{Kesimpulan dan Saran}

Berdasarkan 8 langkah implementasi QCC untuk perbaikan kualitas proses produksi palekat pada Mesin Rapier, diperoleh kesimpulan bahwa terjadinya defect tepi rusak adalah defect paling dominan. Berdasarkan hasil analisis dengan FMEA, diperoleh beberapa rencana perbaikan yang menjadi prioritas dengan nilai RPN terbesar, yaitu: perbaikan pada pemotongan cutter dan proses needle yang tidak sempurna, pengaturan tuckin kurang tepat dan pemasangan benang lusi ke cucuk tidak sesuai SOP. Selanjutnya diberikan beberapa rekomendasi perbaikan untuk mengurangi defect tepi rusak Palekat CR3082 pada mesin Rapier, diantaranya penyetelan ulang pada beem sehingga proses needle akan berjalan dengan sempurna, operator mengatur ulang bagian tuckin pada mesin Rapier sehingga tuckin akan berjalan dengan baik dan untuk karyawan baru maupun lama harus mendapatkan training mengenai pemasangan benang lusi kebagian cucuk agar sesuai SOP. 


\section{Daftar Referensi}

Andre Arief Hendrawan, Yustina, P. (2016). Integrasi Penerapan Kaizen Dan Seven Tools Di Pt . Gunawan. Jurnal Teknik Industri, 6, 1-6.

Darsono. (2013). Analisis Pengendalian Kualitas Produksi Dalam Upaya Mengendalikan Tingkat Kerusakan Produk. JURNAL EKONOMI - MANAJEMEN AKUNTANSI, 35, 1-17.

Desy, I., Hidayanto, B. C., \& Astuti, H. M. (2014). Penilaian Risiko Keamanan Informasi Menggunakan Metode Failure Mode and Effects Analysis di Divisi TI PT. Bank XYZ Surabaya. Seminar Nasional Sistem Informasi Indonesia, September, 467-472.

Fachry Hafid, M., \& Muh Syukur Yusuf, A. (2018). Analisis Penerapan Quality Control Circle Untuk Meminimalkan Binning Loss Pada Bagian Receiving Pt. Hadji Kalla Toyota Depo Part Logistik Makassar. Journal of Industrial Engineering Management, 3(2), 1. https://doi.org/10.33536/jiem.v3i2.228

Khamaludin, K., \& Respati, A. P. (2019). Implementasi Metode QCC untuk Menurunkan Jumlah Sisa Sampel Pengujian Compound. Jurnal Optimasi Sistem Industri, 18(2), 176. https://doi.org/10.25077/josi.v18.n2.p176185.2019

Nasution, A. Y., Yulianto, S., \& Ikhsan, N. (2018). Implementasi Metode Quality Control Circle untuk Peningkatan Kapasitas Produksi Propeller Shaft di PT XYZ. Jurnal Mesin Teknologi, 12(1), 33-39. sintek: JURNAL MESIN TEKHomepage: http://jurnal.umj.ac.id/index.php/sintek Puspitasari, N. B., \& Martanto, A. (2014). Penggunaan Fmea Dalam Mengidentifikasi Resiko Kegagalan Proses Produksi Sarung Atm (Alat Tenun Mesin) (Studi Kasus Pt. Asaputex Jaya Tegal).J@Ti Undip : Jurnal Teknik Industri, 9(2), 93-98. https://doi.org/10.12777/jati.9.2.93-98

Rahayu, Y., Riyanto, A., \& Ramdhani, L. S. (2020). Perlakuan Akuntansi Yang Tepat Terhadap Produk Cacat Pada Perusahaan Berdasarkan Pesanan. Jurnal Ilmiah Ilmu Ekonomi, 9(1), 1-9.

Ratnadi, \& Suprianto, E. (2016). PENGENDALIAN KUALITAS PRODUKSI MENGGUNAKAN ALAT BANTU STATISTIK ( SEVEN TOOLS ) DALAM UPAYA MENEKAN TINGKAT. INDEPT, 6(2), 10-18.

Wicaksono, L. D., \& Syahrullah, Y. (2020).
Perbaikan Kualitas Produk Pengecoran Logam Dengan Menggunakan Metode Quality Control Circle (Qcc). Heuristic, 17(1), 29-42. https://doi.org/10.30996/he.v17i1.3569

Windarti, T. (2014). Pengendalian Kualitas Untuk Meminimasi Produk Cacat Pada Proses Produksi Besi Beton.J@Ti Undip : Jurnal Teknik Industri, 9(3), 173-180. https://doi.org/10.12777/jati.9.3.173-180 